\title{
HUBUNGAN DAYA LEDAK OTOT TUNGKAI, KOORDINASI MATA TANGAN DAN KELENTUKAN TERHADAP KEMAMPUAN SMASH ATLET BOLA VOLI
}

\author{
Didin Tohidin ${ }^{1}$, Netti Afrina ${ }^{2}$, Syafruddin $^{3}$, Muhammad Sazeli Rifki ${ }^{4}$ \\ ${ }^{1234}$ Universitas Negeri Padang, IImu Keolahragaan, Padang, Indonesia \\ didintohidin@fik.unp.ac.id, nettiafrina@gmail.com, syafruddin@fik.unp.ac.id,
} msr rifki@fik.unp.ac.id

\begin{abstract}
To identify factors that affect causal positively, on the performance of smash athletes who have categories of ugly, good, and very good. This, it is necessary to prove the factor of smash movement, namely on the explosiveness of the leg muscles, waist flexibility, and eye-hand coordination. This type of quantitative research research uses correlation research design with causal associative methods. The population in this study was 90 people. Sampling technique uses probability sampling technique, which is a sampling technique that provides the same opportunity for each element / member of the population to be selected to be a sample member, while the number of samples in this study is 29 people. Data is collected using measurements of all three variables. For the explosiveness of the leg muscles in the test with vertical jump, eye-hand coordination with the ball glue test, flexibility with the kayang test. While the ability to smash is measured by the test of smash ability. The data was analyzed with a double regression of three predictors. Based on the results of the data analysis showed that: The explosive power of the significantifiksn tungkaisecara muscle has an effect on the accuracy of the smash $(p<0.05)$ or $\mathrm{HO}$ rejected. Hand eye coordination is significantifiksn to affect the accuracy of smash $(\mathrm{p}<0.05)$ or $\mathrm{HO}$ rejected. The suppleness of the waist is significant significantksn effectively on the accuracy of the smash $(\mathrm{p}<0.05)$ or $\mathrm{H} 0$ rejected. Conclusion, After observing that, there is a causalpositive effect of the explosiveness of the limb muscles, hand eye coordination, and waist flexibility to the performance of athletes.
\end{abstract}

Keywords: Limb Muscle Explosiveness, Eye-hand Coordination, Waist Flexion, and Smash Ability

\begin{abstract}
Abstrak
Untuk mengidentifikasi faktor yang berpengaruh causal secara positif, pada kinerja smash atlet yang memiliki kategori jelek, baik, dan baik sekali. Hal ini, perlu dilakukan pembuktian pada faktor gerakan smash yaitu pada daya ledak otot tungkai, kelentukan pinggang, dan koordinasi mata-tangan. Jenis penelitian penelitian kuantitatif menggunakan desains penelitian korelasi dengan metode asosiatif kausal. Populasi dalam penelitian ini berjumlah 90 orang. Teknik pengambilan sampel menggunakan teknik probability sampling, yaitu teknik pengambilan sampel yang memberikan peluang yang sama bagi setiap unsur/anggota populasi untuk dipilih menjadi anggota sampel, adapun jumlah sampel dalam penelitian ini adalah 29 orang. Data dikumpulkan dengan menggunakan pengukuran terhadap ketiga variabel. Untuk daya ledak otot tungkai di tes dengan vertical jump, koordinasi mata-tangan dengan tes lempartangkap bola, kelentukan dengan tes kayang. Sedangkan kemampuan smash diukur dengan tes kemampuan smash. Data dianalisis dengan regresi ganda tiga prediktor. Berdasarkan hasil analisis data menunjukkan bahwa: Daya ledak otot tungkai secara signifikan berpengaruh positif terhadap ketepatan smash $(p<0,05)$ atau $\mathrm{H}_{0}$ ditolak. Koordinasi mata tangan secara signifikan berpengaruh positif terhadap ketepatan smash $(p<0,05)$ atau $\mathrm{H}_{0}$ ditolak. Kelentukan
\end{abstract}


pinggang secara signifikan berpengaruh positif terhadap ketepatan smash $(p<0,05)$ atau $\mathrm{H}_{0}$ ditolak. Kesimpulan, Setelah diamati bahwa, ada pengaruh causal positif daya ledak otot tungkai, koordinasi mata tangan, dan kelentukan pinggang terhadap kinerja smash atlet.

Kata Kunci: Daya Ledak Otot Tungkai, Koordinasi Mata-tangan, Kelentukan Pinggang, dan Kemampuan Smash

\section{PENDAHULUAN}

Keterampilan teknik dalam permainan bolavoli meliputi: servis, passing, umpan (set up), smash (spike), dan bendungan (block). Dalam permainan bolavoli, salah satu unsur utama yang penting adalah smash. Ketempatan sebagai Smash er haruslah digunakan sebaik-baiknya untuk melakukan serangan karena bola yang akan dipukul sepenuhnya dibawah kendali smash er itu sendiri, kemana saja bola diarahkan dan seberapa keras pukulannya yang diinginkan tergantung pada smash er. Kalau diperhatikan smash merupakan suatu teknik yang mempunyai gerakan yang kompleks yang terdiri dari :1). Langkah awalan, 2). Tolakan untuk meloncat, 3). Memukul bola saaat melayang di udara, 4). Saat mendarat kembali setelah memukul bola.

Bolavoli Putra Junior Sumatera Barat adalah salah salah satu kegiatan olahraga yang melakukan pembinaan dan pemantauan atlet untuk persiapan yang masa akan datang khususnya untuk Provinsi Sumatera Barat. Selain itu, juga merupakan tempat untuk menyalurkan bakat, minat serta untuk memperdalam kemampuan mereka dalam bermain bolavoli. Pada di Bolavoli Putra Junior Sumatera Barat terdapat sarana dan prasarana yang dapat menunjang proses latihan dan pembinaan prestasi atlet.

Perkembangan olahraga bolavoli dilaksanakan pada bolavoli Putra Junior Sumatera Barat dalam bentuk pembinaan. Dalam kegiatan pembinaan yang dilakukan diharapkan pemain menguasai setiap teknik dalam bermain bolavoli salah satunya adalah teknik smash. Smash merupakan pukulan yang utama dalam penyerangan dalam usaha mencapai kemenangan. Untuk mencapai keberhasilan yang gemilang dalam melakukan smash ini diperlukan raihan yang tinggi dan kemampuan meloncat yang tinggi. Smash yang baik dan terarah suatu tim akan berkesempatan memperoleh angka yang lebih besar.

Berdasarkan fakta di atas diduga banyak faktor yang mempengaruhi kemampuan smash yang dimiliki pemain bolavoli seperti; faktor kondisi fisik dan faktor psikologis. Adapun faktor fisik yaitu; kecepatan reaksi, dimana waktu reaksi sederhana dianggap sebagai kemampuan penting untuk segala bentuk olahraga salah satunya adalah olahraga bolavoli, terutama dalam kaitannya dengan rangsangan visual untuk melakukan smash (Bradley, P.S. and Portas, M.D. 2007). 
Kecepatan reaksi digambarkan sebagai interval waktu antara presentasi dari rangsangan yang tidak diantisipasi dan permulaan respon dari seseorang untuk dapat melakukan smash(Schmidt \& Wrisberg, 2000). tetapi juga mewakili waktu individu untuk membuat keputusan dan memulai tindakan, yang dianggap sebagai salah satu ukuran terpenting dalam kinerja dalam banyak situasi seperti pada saat melakukan smash (Ando et al., 2005).

Kelentukan (fleksibilitas) sendi panggul. Kelentukan yang baik dapat menyesuaikan dengan beban eksternal, sehingga dapat memperkecil kemungkinan untuk cedera. Sebaliknya, kekakuan muskulotendinous merupakan salah satu faktor intrinsik untuk cedera (Witvrouw E, Danneels $\mathrm{L}$, Asselman P, D'Have T, Cambier D. 2003; Henderson G, Barnes CA, Portas MD 2010; Nelson, R.T. and Bandy, W.D. 2004). Oleh sebab itu, kelentukan berpengaruh terhadap lecutan pinggang dan kaki pada saat melakukan smash bolavoli.

Selain itu, daya ledak otot tungkai dapat mempengaruhi smash yang dilakukan, dimana tinggi rendahnya lompatan disebabkan oleh daya ledak otot tungkai yang baik. Hal ini disebabkan karena, daya ledak otot tungkai penentu utama kesuksesan dalam melakukan lompatan dengan waktu sesingkat mungkin (Carlsson et al. 2016). Karena daya ledak otot tungkai berkontribusi untuk menghasilkan tenaga penggerak pada tingkat yang bervariasi selama melompat. (Österas et al. 2002; Holmberg et al. 2005).

Smash yang dilakuka, dapat diasumsikan bahwa smash menuntut rentang gerak ekstremitas atas dengan kecepatan tinggi. Dengan demikian, untuk pemahaman yang lebih lengkap tentang efek fase gerakan smash, kami melkukan analisis tentang pengaruh daya ledak otot tungkai, koordinasi mata tangan, dan kelentukan pinggang pada kinerja smash bolavoli

\section{METODELOGI PENELITIAN}

Penelitian ini merupakan penelitian kuantitatif dengan desain korelasional. Populasi dalam penelitian ini adalah atlet bolavoli Putra Junior Sumatera Barat. Sampel dalam penelitian ini diambil secara Probability sampling yaitu sampel berjumlah 29 orang. Untuk memverifikasi hipotesis yang diusulkan maka, perlu melakukan pengukuran yang berkaitan dengan daya ledak otot tungkai, koordinasi mata tangan, dan kelentukan pada smash (Bui et al., 2019; Fiske, Cuddy, \& Glick, 2007). Jadi, untuk mendapatkan informasi tentang pengaruh variabel yang diajukan khusus olahraga Tenis, maka data yang dikumpulkan dalam penelitian ini adalah data primer yang diambil dari responden tes, yang terdiri dari, vertical jump untuk mengukur daya ledak otot tungkai, flexiometer (kayang) untuk mengukur kelentukan pinggang, lempar tangkap bola untuk mengukur koordinasi mata-tangan, 
JURNAL SPORTA SAINTIKA

P-ISSN 2505-5651

E-ISSN 2579-5910

kemampuan smash untuk mengukur kemampuan smash. Pertama, statistik deskriptif diperiksa untuk menggambarkan kemampuan umum daridaya ledak otot tungkai, koordinasi mata tangan, dan kelentukan pinggang terhadap passing bawah bolavoli. Kedua, untuk menilai pengaruh causal antara variabel yang diusulkan yaitu memanfaakan IBM SPSS software. Signifikansi ditentukan pada tingkat $p<0,05$.

\section{HASIL PENELITIAN}

Pengaruh utama dalam penelitian ini adalah pengaruh ledak otot tungkai, koordinasi mata tangan, dan kelentukan terhadap smash. Berdasarkan analisis yang dilakukan dari hasil sebelumnya dapat dilaporkan bahwa:

\begin{tabular}{|c|c|c|c|c|c|c|}
\hline \multicolumn{7}{|c|}{ Tabel 1. Tests of Normality } \\
\hline & \multicolumn{3}{|c|}{ Kolmogorov-Smirnov } & \multicolumn{3}{|c|}{ Shapiro-Wilk } \\
\hline & Statistic & df & sig & Statistic & df & sig \\
\hline $\begin{array}{l}\text { Daya ledak otot } \\
\text { tungkai }\end{array}$ & ,083 & 29 & ,200* & ,969 & 29 &, 541 \\
\hline Kordinasi & ,146 & 29 & 114 & ,935 & 29 & ,075 \\
\hline Kelentukan & ,213 & 29 & ,102 & ,848 & 29 & ,001 \\
\hline Smash & 109 & 29 & ,200* & ,948 & 29 & 159 \\
\hline
\end{tabular}

Dari output di atas, diperoleh: Harga statistic untuk Kolmogorov-Smirnov sebesar 0,083 dan sig atau $p$-value $=0,200>0,5$ untuk koordinasi, 0,146 dan sig atau $p$-value $=0,114>0,5$ untuk kelentukan, dan 0,213 dan sig atau $p$-value $=0,102>0,5$ untuk smash 0,109 sig atau $p$-value $=0,102>0,5 . \mathrm{H}_{0}$ diterima atau tidak signifikan. Dengan demikian data ledak otot tungkai, koordinasi mata tangan, dan kelentukan terhadap smash berdistribusi normal. Untuk lebih jelasnya dapat dilihat pada diagram normal Quantile and Quantil (Q-Q) plot. 
JURNAL SPORTA SAINTIKA
P-ISSN 2505-5651

E-ISSN 2579-5910

Tabel 2. Test of Homogeneity of Variance
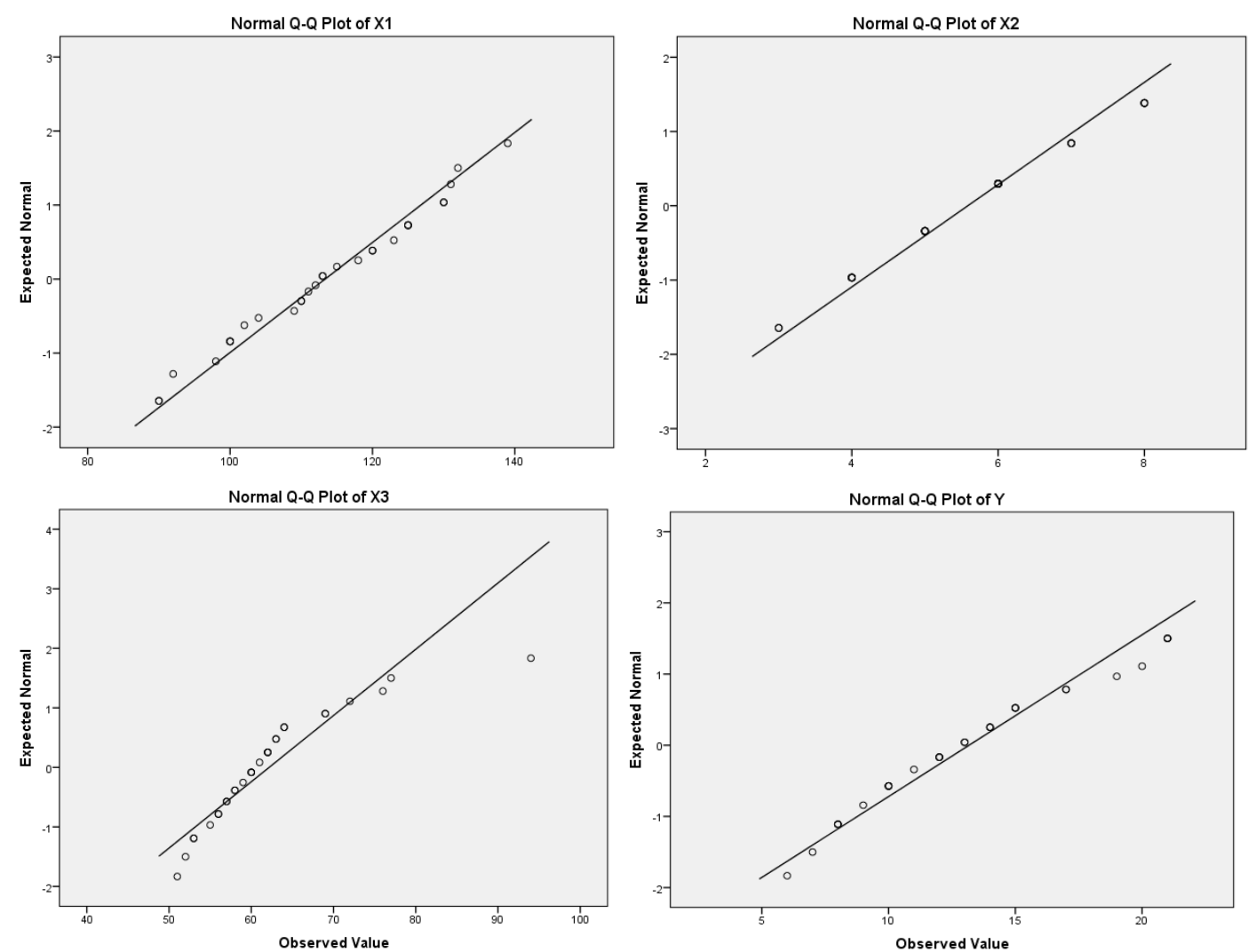

statistic berdasarkan seluruh kriteria dengan nilai sig, seluruhnya di atas 0,05. Karena nilai sig $>0,05$, maka dapat disimpulkan variable $X_{1}, X_{2}, X_{3}$ dan $Y$ berasal dari populasi yang homogen.

\begin{tabular}{|l|r|r|r|r|r|}
\hline \multicolumn{7}{|c|}{ Tabel 3. Descriptive Statistics } \\
\hline $\begin{array}{l}\text { Variabel } \\
\text { Daya ledak otot }\end{array}$ & $\mathrm{N}$ & Minimum & Maximum & Mean & $\begin{array}{c}\text { Std. } \\
\text { Deviation }\end{array}$ \\
\hline Kungkai & 29 & 90,00 & 139,00 & 113,3448 & 13,45170 \\
\hline Koordinasi & 29 & 3,00 & 8,00 & 5,5862 & 1,45202 \\
\hline Selentukan & 29 & 51,00 & 94,00 & 62,1724 & 8,98439 \\
\hline Valid N (listwise) & 29 & 6,00 & 21,00 & 13,1724 & 4,40024 \\
\hline
\end{tabular}


JURNAL SPORTA SAINTIKA

P-ISSN 2505-5651

E-ISSN 2579-5910

\section{Persamaan linear ganda dan uji signifikansi koefisien persamaan regresi}

\begin{tabular}{|c|c|c|c|c|c|}
\hline \multicolumn{6}{|c|}{ Tabel 4. Coefficients ${ }^{a}$} \\
\hline \multirow{2}{*}{ Model } & \multicolumn{2}{|c|}{$\begin{array}{l}\text { Unstandardized } \\
\text { Coefficients }\end{array}$} & \multirow{2}{*}{$\begin{array}{c}\text { Standardized } \\
\text { Coefficients } \\
\text { Beta } \\
\end{array}$} & \multirow[t]{2}{*}{$\mathrm{t}$} & \multirow[t]{2}{*}{ Sig. } \\
\hline & $\mathrm{B}$ & Std. Error & & & \\
\hline (Constant) & 14.919 & 5.247 & & -2.843 & .009 \\
\hline $\begin{array}{l}\text { Daya ledak otot } \\
\text { tungkai }\end{array}$ & .111 & .048 & .340 & 2.305 & .030 \\
\hline $\begin{array}{l}\text { Koordinasi mata } \\
\text { tangan }\end{array}$ & .794 & .289 & .373 & 2.752 & .011 \\
\hline $\begin{array}{l}\text { Kelentukan } \\
\text { pinggan }\end{array}$ & .156 & .072 & .319 & 2.158 & .041 \\
\hline
\end{tabular}

Dari table Coefficients, pada kolom B diperoleh konstanta $b_{0}=-14,919$ koefesien $b_{1}=0,111$, $b_{1}=794$ dan $b_{3}=1,59$. Sehingga persamaan regresi linear ganda adalah $\hat{Y}=-14,919+0,111 X_{1}+$ $0,791 X_{2}+, 791 X_{3}$. Hipotesis: $H_{0}: \beta_{1}>0 . H_{0}: B_{2}>0$, dan $H_{0}: B_{3} \leq 0$. Dari hasil analisis dari table tersebut menunjukan harga statistic untuk koefesien variable $X_{1}$ yaitu $t_{\text {hit }}=2,30$ dan $p$-value $=0,030 / 2=0,015<$ 0,05 (uji pihal kanan), atau $\mathrm{H}_{0}$ ditolak, yang bermakna daya ledak otot tungkai berpengaruh positif terhadap Smash,dan harga statistic untuk koeesien variabel $X_{2}$ yaitu $t_{\text {hit }}=2,75$ dan $p$-value $=0,011 / 2$ $=0,006<0,05$ (uji pihal kanan), atau $\mathrm{H}_{0}$ ditolak, yang bermakna koordinasi mata tangan berpengaruh positif terhadap Smash.Selanjutnya harga statistic untuk koeesien variabel $X_{3} y$ aitu $t_{\text {hit }}=2,16$ dan $p$ value $=0,041 / 2=0,021<0,05$ (uji pihal kanan), atau $\mathrm{H}_{0}$ ditolak, yang bermakna kelentukan pinggang berpengaruh positif terhadap Smash.

\section{Uji signifikan persamaan regresi ganda}

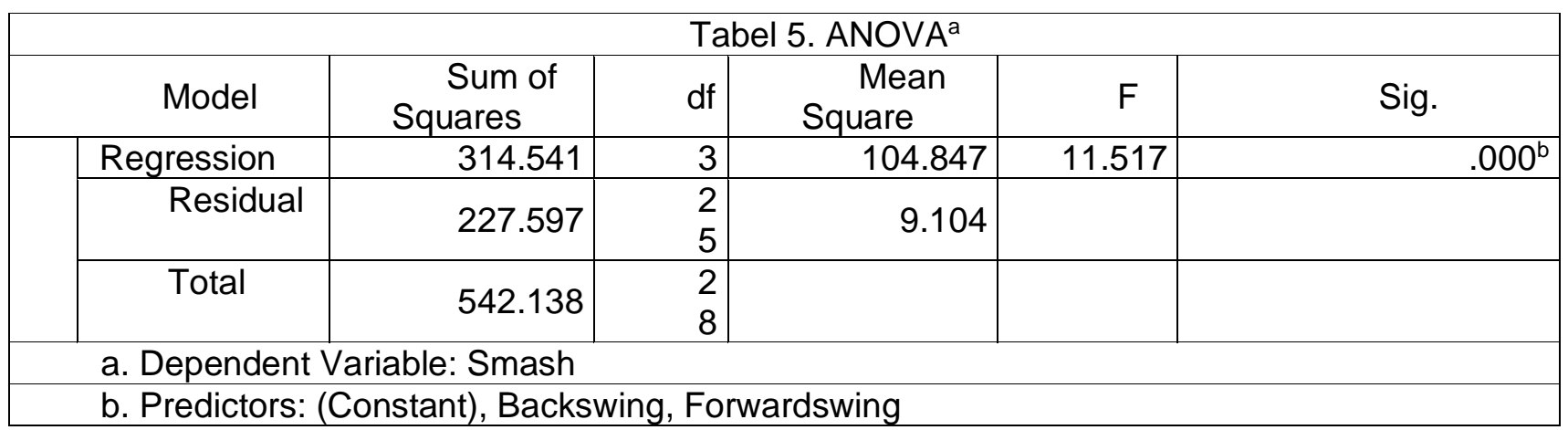


JURNAL SPORTA SAINTIKA

P-ISSN 2505-5651

E-ISSN 2579-5910

Dari hasil hasil analisis yang dilakukan pada table SNOVA di atas diperoleh, harga statistic F, yaitu $F_{\text {hit }}=11,517$, dan $p$-value $=0,000<0,05$ yang berarti $H_{0}$ ditolak. Dengan demikian dapat disimpulkan bahwa, terdapat pengaruh linear variabel daya ledak otot tunmgkai, koordinasi mata tangandan kelentukan pinggang dengan Smash. Hal ini juga terdapat pengaruh bersama-sama (simultan) daya ledak otot tunmgkai, koordinasi mata tangan dan kelentukan pinggang terhadap Smash.

\section{Uji signifikansi koefesien korelasi ganda}

\begin{tabular}{|c|c|c|c|c|c|c|c|c|c|}
\hline \multirow[b]{3}{*}{ Model } & \multicolumn{9}{|c|}{ Tabel 6. Model Summary } \\
\hline & & & & Std. & & & ige St & & \\
\hline & & $\begin{array}{c}\text { Squar } \\
\text { e }\end{array}$ & $\begin{array}{c}\text { Adjusted } \\
\text { R } \\
\text { Square }\end{array}$ & $\begin{array}{l}\text { Error of } \\
\text { the } \\
\text { Estimate }\end{array}$ & $\begin{array}{c}\mathrm{R} \\
\text { Square } \\
\text { Change }\end{array}$ & F Change & df1 & df2 & $\begin{array}{l}\text { Sig. F } \\
\text { Change }\end{array}$ \\
\hline 1 & $762^{\mathrm{a}}$ & 580 & $\begin{array}{r}.53 \\
0\end{array}$ & $\begin{array}{r}3.01 \\
7\end{array}$ & $9^{.84}$ & 78.583 & 2 & 27 & .000 \\
\hline
\end{tabular}

Uji koefesien korelasi ganda diperolah dari table Model Summary di atas, terlihat bahwa koefesien korelasi ganda $\left(R_{y .123}\right)=0,762$ demikian koefesien korelasi ganda anatara $X_{1}, X_{2}, X_{3}$ dan $Y$ adalah berarti atu signifikan. Sedangkan koefesien derteminasi ditunjukan oleh $R$ Square $=0,580$, yang mengandung makna bahwa, 58\% variabilitas variabel Smash (Y) dapat dijelaskan oleh daya ledak otot tungkai $\left(X_{1}\right)$, koordinasi mata tangan $\left(X_{2}\right)$, dan kelentukan pinggang $\left(X_{3}\right)$ sehingga dapat disimpulkan bahwa pengaruh $X_{1}, X_{2}$, dan $X_{3}$ secara bersama-sama (simultan) terhadap Smash sebesar $58 \%$.

\section{PEMBAHASAN}

Hasil kami menunjukan pengaurh yang tinggi secara causal dari variable daya ledak otot tungkai, koordinasi mata tangan, dan kelentukan pinggangterhadap kemampuan smash. Tiga variable yang diusulkan terjadi pengaruh secara bersama (simultan) positif terhadap ketepatan smash (Table 6). Temuan ini, mirip dengan sebelumnya dilakukan oleh peneliti lain bahwa,sudut gerakan scapula pada fase daya ledak otot tungkai, koordinasi mata tangan, dan kelentukan pinggang berkontribusi terhadap ketepatan smash(Rogowski, Creveaux, Chèze, \& Dumas, 2014).

Secara empiris, telah ditemukan bahwa pengaruh antara variabel kajian yang ditemukan dalam penelitian ini yang menyatakan bahwa kemampuan melakukan smash memiliki pengaruh yang signifikan daya ledak otot tungkai, koordinasi mata-tangan, dan kelentukan pinggang. Pengaruh ini 
menjadi salah satu sumber untuk dapat meningkatkan kemampuan kinerja dari smash atlet. Hal ini, perlu adanya penyusunan program latihan yang terkait dengan hasil temuan secara empiris tersebut.

Peningkatan kemampuan smash harus didukung oleh unsur kondisi fisik seperti daya ledak otot tungkai Di sejumlah cabang olahraga, kemampuan untuk menghasilkan dan mentransfer daya ledakadalah elemen kunci sukses. Evaluasi berbagai ekspresi kekuatan dan daya ledak, serta faktorfaktor yang berkontribusi padanya. Oleh karena itu, daya ledak otot tungkai sangat penting untuk meningkatkan kinerja gerakan dalam olahraga (Stockbrugger \& Haennel 2003). Sejumlah tes lapangan menilai daya ledak telah digunakan untuk memberikan umpan balik kepada atlet tentang penampilannya. Beberapa dari tes yang paling umum digunakan untuk menilai kekuatan dan kecepatan tubuh bagian bawah yaitu vertikal (Johnson and Bahamonde 1996; Stockbrugger and Haennel 2001). Kemudian, melakukan smash dalam bolavoli telah disarankan sebagai metode yang tepat untuk menilai total tubuh, yang berkaitan dengan daya ledak otot tungkai pada atlet (Stockbrugger \&Haennel 2001). Karena dinilai daya ledak otot tungkai terintegrasikan dalam gerakan dan khusus untuk kinerja olahraga seperti melakukan smash (Clark 2001).

Untuk melakukan smash yang efektif, diperlukan pola yang sangat terkoordinasi mata dan tangan serta aktivitas otot tubuh secara total (Smith, M. F. 2010). Dengan mengadopsi gerakan antarsegmen yang tersinkronisasi dan selaras dari ekstremitas bawah ke atas, penyerang diminta untuk mendeteksi pola lintasan bola dan posisi pertahanan secara tepat, dengan ini maka smash yang dilakukan menjadi tepat (Sarvestan et al., 2018).

Jadi pada prinsipnya, sistem kontrol motorik secara terus menerus berusaha untuk menjaga pola koordinasi mata dan tangan serta seluruh tubuh dan mengadopsi strategi pengendalian untuk mengimbangi gangguan internal dan eksternal(Shafizadeh et al., 2018), dalam melakukan smash. Penelitian ini mendapatkan pengaruh yang sama dengan penelitian yang dilakukan oleh (Pratama, M. N., \& Rahayu, S. 2014;Andrijas, A. 2020) dimana, koordinasi mata-tangan berpengaruh terhadap kemampuan smashbolavoli.

Selain itu, kelentukan pinggang menjadi salah satu faktor yang ikut berkontribusi dalam keberhasilan melakukan smash.Kelentukan pinggang dapat dinilai dengan pengukuran langsung dari berbagai gerakan dan melalui penggunaan alat penilaian tidak langsung, seperti tes duduk dan jangkauan (Nelson and Bandy, 2004; Bradley and Portas, 2007).

Penggunaan intervensi pelatihan multifaktorial setuju bahwa kelentukan pinggang sangat penting untuk mekanisme ayunan yang optimal, meskipun fleksibilitas pinggang telah terbukti berpengaruh secara negatif oleh perkembangan hipertrofi otot (Gergley,2009; Keogh et al.,2009). 
Salah satu komponen fisik yang telah diselidiki secara individu adalah pengaruh kelentukan pinggang terhadap performa dalam berbagai cabang olahraga salah satunya bolavoli (Hume, Keogh, \& Reid,2005). Kelentukan pinggang pada pemain dengan kemampuan lebih, atau lebih rendah telah ditemukan secara signifikan lebih besar daripada rekan mereka yang lebih berkemampuan tinggi(Sell, Tsai, Smoliga, Myers, \& Lephart,2007). Artinya pemain yang memiliki kecepatan pukulan rendah dengan memiliki kelentukan pinggang akan berpengaruh terhadap pukulan yang dilakukan pada saat smash .

Jadi seorang pemain dengan kemampuan smash rendah yang menunjukkan kelentukan pinggang yang lebih besar selama melakukan smashpada bolavolimaka, dapat mencapai posisi tertentu (ayunan atas ke belakang) dengan peningkatan keseimbangan dan kontrol, untuk menghasilkan kecepatan pukulan yang lebih cepat dan tepat (Sell et al.,2007; Smith,2010).

\section{KESIMPULAN}

Studi ini menyoroti pengaruh daya ledak otot tungkai, koordinasi mata tangan, dan kelentukan pinggang terhadap kemampuan smash dari pemain bolavoli putra junior yang kompetitif. Pukulan smash menuntut daya ledak otot tungkai, koordinasi mata tangan, dan kelentukan pinggang yang lebih baik dengan pronasi lengan lebih banyak selama melakukan smash. Penelitian ini memberikan wawasan berbasis bukti pengaruh dari ketiga komponen kondisi fisik utama yang tinggi terhadap ketepatan smash bolavoli.

\section{DAFTAR PUSTAKA}

Ando, S., Kimura, T., Hamada, T., Kokubu, M., Moritani, T., \& Oda, S. (2005). Increase in reaction time for the peripheral visual field during exercise above the ventilatory threshold. European Journal of Applied Physiology,94, 461-467. doi:10.1007/s00421-005-1330-7

Bradley, P.S. and Portas, M.D. (2007). The relationship between preseason range of motion and muscle strain injury in elite soccer players. Journal of Strength and Conditioning Research, 21, 1155-1159.

Bui, K. L., Maia, N., Saey, D., Dechman, G., Maltais, F., Camp, P. G., \& Mathur, S. (2019). Reliability of quadriceps muscle power and explosive force, and relationship to physical function in people with chronic obstructive pulmonary disease: an observational prospective multicenter study. Physiotherapy Theory and Practice. https://doi.org/10.1080/09593985.2019.1669233

Clark MA (2001) Integrated Training for the New Millennium. Thousand Oaks, CA: National Academy of Sports Medicine.

Gergley, J. (2009). Acute effects of passive static stretching during warm-upon driver clubhead speed, 
distance, accuracy, and consistent ball contactin young male competitive golfers.Journal of Strength and ConditioningResearch,23(3),863-867. doi:10.1519/JSC.0b013e3181a00c67.

Henderson G, Barnes CA, Portas MD (2010). Factors associatedwith increased propensity for hamstring injury in EnglishPremiet League soccer players. J Sci Med Sport 13: 397-402.

Hume, P. A., Keogh, J., \& Reid, D. (2005). The role of biomechanics inmaximising distance and accuracy of golf shots.Sports Medicine,35(5),429-449. doi:10.2165/00007256-20053505000005

Johnson DL, Bahamonde R (1996) Daya ledak otot tungkai output estimate in university athletes. Journal of Strength and Conditioning Research 10: 161-16

Keegan, R. J., Spray, C. M., Harwood, C. G., \& Lavallee, D. (2014). A qualitative investigation of the motivational climate in elite sport. Psychology of Sport and Exercise. https://doi.org/10.1016/j.psychsport.2013.10.006

Keogh, J. W. L., Marnewick, M. C., Maulder, P. S., Nortje, J. P., Hume, P. A., \&Bradshaw, E. J. (2009). Are anthropometric, flexibility, muscularstrength, and endurance variables related to clubhead velocity in lowand high handicap golfers? Journal of Strength and Conditioning Research,23(6), 1841-1850.doi:10.1519/jsc.0b013e3181b73cb3

Meng, L., Pei, G., Zheng, J., \& Ma, Q. (2016). Close games versus blowouts: Optimal challenge reinforces one's intrinsic motivation to win. International Journal of Psychophysiology. https://doi.org/10.1016/.i.jpsycho.2016.11.001

Nelson, R.T. and Bandy, W.D. (2004). Eccentric training and static stretching improve hamstring flexibility of high school males. Journal of Athletic Training, 39, 254-258.

Österas H, Helgerud J, Hoff $\mathrm{J}$ (2002). Maximal strength-training effects on force velocity and forcedaya ledak otot tungkairelationships explain increases in aerobic perfor-mance in humans. European Journal of AppliedPhysiology, 88(3): 255-263.

Pratama, E. P., \& Alnedral, A. (2018). Kontribusi Daya Ledak Otot Tungkai dan Koordinasi Mata Tangan Terhadap Ketepatan Smash Bolavoli. Jurnal JPDO, 1(1), 135-140.

Rogowski, I., Creveaux, T., Chèze, L., \& Dumas, R. (2014). Scapulothoracic kinematics during tennis smash. Sports Biomechanics. https://doi.org/10.1080/14763141.2014.885073

Sarvestan, J., Cheraghi, M., Sebyani, M., Shirzad, E., \& Svoboda, Z. (2018). Relationships between force-time curve variables and jump height during countermovement jumps in young elite volleyball players. Acta Gymnica, 48(1), 9-14.

Sell, T. C., Tsai, Y., Smoliga, J. M., Myers, J. B., \& Lephart, S. M. (2007). Strength, flexibility, and balance characteristics of highly proficient golfers. Journal of Strength and Conditioning Research,21(4), 1166-1171. doi:10.1519/r-21826.

Smith, M. F. (2010). The role of physiology in the development of golf performance. Sports 
JURNAL SPORTA SAINTIKA

P-ISSN 2505-5651

E-ISSN 2579-5910

Medicine,40(8), 635-655. doi:10.2165/11532920-000000000-00000

Stockbrugger BA, Haennel RG (2001) Validity and reliability of a medicine ball explosive power test. Journal of Strength and Conditioning Research 15: 431-438.

Stockbrugger BA, Haennel RG (2003) Contributing factors to performance of a medicine ball explosive power test: A comparison between jump and nonjump athletes. Journal of Strength and Conditioning Research 17: 768-774.

West, J. (2015). Testing the hierarchical model of intrinsic and extrinsic motivation at the situational level. Dissertation.

Witvrouw E, Danneels L, Asselman P, D'Have T, Cambier D. (2003). Muscle flexibility as a risk factor for developing muscle injuriesin male professional soccer players. Am J Sports Med 31:41-46. 